HID 45 (2018)

\title{
LA FRONTERA DE GRANADA: ACERCA DEL TERRITORIO Y LA LÍNEA DIVISORIA (SIGLOS XIV Y XV) ${ }^{1}$
}

THE GRANADAN FRONTIER: TERRITORY AND

DEMARCATION LINE (14 ${ }^{\mathrm{TH}}$ AND $15^{\mathrm{TH}}$ CENTURIES)

\author{
José ENRiQue LóPEZ de CoCa CASTAÑER \\ Universidad de Málaga \\ jelopezd@uma.es
}

RESUMEN: En este trabajo demostramos que en la frontera granadina hubo una línea divisoria que marcaba la separación entre el emirato nazarí y el reino de Castilla. Se hace hincapié en las fuentes que nos permiten conocer el trazado de esa línea de demarcación. Y se discuten los caracteres de la franja territorial por la que discurría la divisoria, la cual ha sido vista erróneamente como una especie de tierra de nadie.

PALABRAS ClaVE: Zona fronteriza; línea de demarcación; las fuentes.

ABSTRACT: In this paper we show that in the Granadan frontier there was a dividing line between the Nasrid emirate and the kingdom of Castile. We point out the sources that allow us to know the outline of it. And we discuss about the strip of land that line runs, which has been seen wrongly as a sort of no man's land.

KEYWORDS: Frontier area; dividing line; the sources.

\section{INTRODUCCIÓN}

Con la consolidación del reino de Granada en la segunda mitad del siglo XIII, la frontera entre la Cristiandad y el Islam en la Península Ibérica se estabiliza, deja de ser móvil y, por tanto, imprecisa. Esto no excluye que se produzcan pequeños reajustes, más algunas modificaciones importantes como resultado de las conquistas de Algeciras (1344) y Antequera (1410), sobre todo. Pero si las zonas por don-

Recibido: 22-5-2018; Aceptado: 16-7-2018; Versión definitiva: 16-9-2018.

1. Abreviaturas utilizadas: $\mathrm{ACM}=$ Archivo Catedral Málaga; $\mathrm{ARChGr}=$ Archivo Real Chancillería Granada; AGS = Archivo General Simancas; AMS = Archivo Municipal Sevilla; RGS = Registro General Sello.

Copyright: (C) Editorial Universidad de Sevilla. Este es un artículo de acceso abierto distribuido bajo los términos de la licencia de uso y distribución Creative Commons Reconocimiento-No-ComercialSinObraDerivada 4.0 (CC BY-NC-ND 4.0) 
de discurrían las sucesivas fronteras entre el reino de Castilla y el emirato nazarí se han conocido de siempre, la delimitación de su trazado ha pasado a menudo inadvertida para los historiadores.

Queremos mostrar cómo la frontera estuvo delimitada por hitos, mojones o accidentes naturales muy concretos, que señalaban la divisoria y que podrían reducirse a una línea que marcase la separación entre Granada y Castilla. Aunque a uno y otro lado de esa línea hubo franjas territoriales escasamente pobladas e incultas, zonas de paso, de extensión variable, donde había más inseguridad en tiempo de tregua que en tiempo de guerra.

El objeto de este trabajo es oportuno pues se ha llegado a negar la existencia de una línea de demarcación. En lo que toca a la frontera de Jaén con el reino de Granada un historiador tan pronto alude a la "supuesta raya de separación de ambas tierras" como destaca el silencio de las fuentes sobre "esa supuesta línea divisoria de uno y otro lado". Ha sugerido incluso que, en vez de esta línea de separación lo que hubo fue una "amplia zona neutral entre los límites del territorio cristiano y los mojones del granadino". Una especie de zona intermedia que raramente estuvo desocupada pues solía aprovecharse para pastos de forma comunitaria por ambas partes ${ }^{2}$.

\section{LA ZONA FRONTERIZA}

Desde una perspectiva militar, se ha convenido considerar como zona fronteriza la franja de terreno en la cual se peleaba casi continuamente. Sus límites eran los alcanzados por los habitantes de la zona durante sus incursiones en tierra enemiga $^{3}$. Cuando los granadinos entraban en el reino de Jaén, no solían ir más allá de las cuatro o cinco leguas. De ahí la sorpresa provocada por el ataque a Santiago y La Higuera de Martos -lugares de la Orden de Calatrava-, el 29 de septiembre de 1471, lugares que distaban entre ocho y nueve leguas de la línea divisoria con Granada. En una crónica coetánea leemos que los atacantes entraron, finalmente, donde nunca o quasi nunca moros llegaron $\left\lceil. . . J^{4}\right.$. En el caso de la frontera con el reino de Sevilla, la zona de contacto directo de moros y cristianos coincidía con las cordilleras béticas. Más al interior de Andalucía, la Campiña solía estar al abrigo de las incursiones granadinas salvo en la zona suroriental de la misma, que fue objetivo de algaras todavía en el siglo XV. Jerez pudo desarrollar una importante actividad agrícola gracias a que sus tierras estaban bastante lejos de la línea divisoria. En contrapartida, se vio obligada a alimentar a los habitantes de lugares avanzados como Gibraltar y Jimena 5 .

2. Rodriguez Molina 1987, p. 114.

3. Gautier-Dalché 1959 , p. 189.

4. Véase carta del condestable Miguel Lucas de Iranzo al papa Sixto IV (Jaén, 15/octubre/ 1471), en la que denuncia como los moros corren sin cesar la tierra de Jaén gracias a la ayuda indirecta del conde de Cabra y pide indulgencias para quienes vengan a combatir a su lado. Escavias 1940, pp. $470-475$.

5. Carmona Ruiz 2009, p. 251. 
Desde el punto de vista del fisco, la noción de zona fronteriza era otra. Tanto las leyes civiles de Castilla como las eclesiásticas vetaban la exportación de mercancías que pudieran fortalecer a los musulmanes en su lucha contra los cristianos: lo que equivale a decir que estaba prohibido el tráfico de armas, caballos, mulas y trigo. Para impedir el envío de caballos y mulos al otro lado de la frontera, Juan I ordenó en 1380 inscribir en un registro todos los animales de ambas especies existentes en el reino de Murcia dose leguas de contra los mojones de Granada, haciendo constar caracteres tales como su edad, alzada y color ${ }^{6}$. Doce leguas a partir de los límites será, asimismo, el espacio dentro del cual los guardas puestos por el recaudador del diezmo y medio diezmo de lo morisco podían pedir a los mercaderes procedentes de Granada que mostrasen los recibos de haber pagado este impuesto. En caso contrario las mercancías les serían tomadas por descaminado o, lo que es igual, confiscadas?

El tráfico ilegal de ganado se incrementaba cuando las autoridades castellanas limitaban el número de cabezas que se podían llevar a territorio granadino amparándose en lo acordado en algunas treguas. Como en la zona fronteriza abundaban los pastizales -ya fuera por su inseguridad y poca población, o porque el medio natural era apto sólo para el aprovechamiento pastoril $-{ }^{8}$, el ganado que se movía durante el año en el lado andaluz estaba en condiciones de cruzar la línea divisoria a hurtadillas. A instancias del arrendador mayor del diezmo y medio diezmo, en enero de 1478 los RR.CC. advirtieron a los concejos de Sevilla, Córdoba, Jaén y otras ciudades, villas y lugares de su arzobispado y obispados que todo el ganado lanar, cabrío y bovino que se apacentara a menos de 10 leguas de los mojones de la frontera, o que fuera a herbajar allí, había de registrarse ante el alcalde mayor del diezmo y medio diezmo don Hurtado de Mendoza, o ante cualquier teniente o escribano designado al efecto, a fin de impedir que pasara a territorio granadino sin pagar los derechos correspondientes. En diciembre de 1479 los monarcas volvieron a ordenar que los animales que fueran a herbajar desde los mojones de la dicha tierra de moros contra estos nuestros reinos dentro de diez leguas, fuesen inscritos y registrados ante el citado alcalde mayor cada vez que éste lo pidiera9

\section{LA SUPUESTA BANDA TERRITORIAL}

El erudito decimonónico Miguel Lafuente Alcántara escribía que en 1417, durante la vigencia de un período de tregua, ocurrió un grave incidente en la frontera

6. Carta de Juan I al concejo de Murcia (Soria, 8/septiembre/1380) para confirmar un ordenamiento de Enrique II a este respecto, en junio de 1377. Suárez Fernández 1982, II, pp. 188-189 y 418.

7. López de Coca Castañer 2009, passim.

8. La combinación de estos tres factores justificó, en su momento, que la actividad ganadera fuese notable en la frontera. Rodríguez Picavea 2001, pp. 182-203.

9. Carta firmada en Sevilla a 30 de enero de 1478. AGS RGS enero 1478, f. 90. Para la confirmación, ver documento expedido en Toledo el 23 de diciembre de 1479, en Rodríguez Molina (1985), pp. 120-122. Otra copia, en AGS RGS. diciembre 1479, f. 59. López de Coca 2009, p. 388. 
de Jaén y que el emir Yusuf III, a la sazón reinante en Granada, dispuso que dos personas de crédito dirimiesen como árbitros la discordia. La tarea recayó en don Diego Fernández de Córdoba, alfaqueque mayor de Castilla, y Mahomad Handun, alfaquí mayor de Granada, los cuales se reunieron varias veces como jueces de las partes, declararon culpables a los moros y, para evitar nuevos incidentes, determinaron que en todo el radio de la frontera se designara un terreno neutral donde no fuese lícito ni a unos ni a otros conducir sus ganados ${ }^{10}$.

Rodríguez Molina atribuye a los árbitros mencionados el haber bosquejado lo contrario: una franja neutral donde pudieran entrar seguramente los ganados de ambas partes. Sugiere que hubo una larga y ancha banda de tierras de nadie, tierras de pasto común para moros y cristianos, que iría desde Alcalá la Real hasta los términos de Cazorla. Una franja de media legua de anchura más o menos, aunque no está claro si era continua o discontinua. Y cree haber encontrado fragmentos de esa banda territorial en documentos posteriores a la conquista del reino de Granada ${ }^{11}$. No es fácil explicar cómo podían pastar juntos los rebaños de moros y cristianos en zonas donde abundaban los encinares ricos en bellota. Un espacio apetecible para las piaras de cerdos que, por citar un ejemplo, los ganaderos giennenses introducían en la dehesa de Matabegid, sita entre los términos de Jaén y Cambil, en la supuesta banda intermedia ${ }^{12}$. Hay que tener en cuenta, además, que los pastores castellanos les disgustaba mezclar sus ovejas con las granadinas: al considerar las propias más finas, procuraban evitar que los carneros moriscos las montaran ${ }^{13}$.

Argente del Castillo también malinterpreta la sentencia de 1417. Admite, no obstante, que el acuerdo alcanzado entre las partes no debió tener mucha efectividad en la práctica pues en el caso de la dehesa de Matabegid, los testigos presentados por el concejo giennense en el pleito que sostuvo con el de Granada después de 1492, afirman reiteradamente que los ganados propios debían entrar en ella con el permiso de los alcaides moros de Cambil y Alhabar, pues de lo contrario eran prendidos. La realidad, concluye, es que los ganados de ambas partes pasaban a uno y otro lado de la línea divisoria mediante acuerdos particulares de las autoridades locales ${ }^{14}$. Algo similar propone Jiménez Alcázar para la frontera murciana. Opina que no debe contemplarse la línea divisoria como un límite a las cañadas y travesías ganaderas: el aislamiento de la zona, una actitud pragmática y los intereses de los poderosos hicieron que los aprovechamientos fuesen comunes

10. Lafuente Alcántara 1992, III, pp. 85-87. Asimismo, Seco de Lucena Paredes 1958, pp. 137-140.

11. Pleitos de Granada con Jaén y la villa de Huelma. Pleitos entre Cazorla y Quesada. Rodríguez Molina 1987, pp. 118-121. Posteriormente volverá sobre el tema, reproduciendo el texto publicado en 1987 con algunas disquisiciones adicionales. Rodríguez Molina 1997, pp. 257-264 y 272-274 en particular.

12. En la disputa de Jaén con el duque de Alburquerque se dice que en tiempo de moros entraban en Matabegid los cristianos con “puercos e ovejas”. Rodríguez Molina 1985, p. 258.

13. Después de la guerra se prohíbe a los mudéjares de Orce y Galera aprovechar los pastos de la sierra de Huéscar a fin de que sus rebaños no se mezclen con los del condestable de Navarra, dueño de aquellos predios por merced real. Los motivos son los arriba citados. Pérez Boyero 1997, pp. 207-208.

14. Argente del Castillo Ocaña 1988, pp. 271-280. 
en muchos tramos de la línea, se arrendasen pastizales unos a otros, o simple y llanamente, continuaran utilizándose las cañadas en los períodos de tregua ${ }^{15}$.

Pero esa trashumancia en ambos sentidos sólo está documentada en circunstancias excepcionales. El pleito entre Jaén y Huelma (1486) por el uso de los pastos de Matabegid recoge declaraciones de testigos reconociendo que, en tiempo de tregua, los alcaides de Cambil y Alhabar arrendaban el término de Bexis a los ganaderos cristianos. Y añaden que al tienpo que la dicha villa de Huelma, cabecera del distrito, y los dichos lugares de Canbil y Alhabar eran de moros, la villa citada poseía el término de Bexis pacíficamente, e prendavan a todos los vezinos de Canbil e Alhabar que tomavan paçiendo e roçando o caçando dentro del dicho término y ellos le pagavan las prendas llanamente. Conquistada Huelma por los castellanos, serán sus alcaides quienes prendan a los moros de Cambil y Alhabar, cuando los encuentren paçiendo e roçando o caçando dentro del dicho término, en el tienpo que avía tregua entre los moros e christianos ${ }^{16}$.

En este caso la inercia explica que los pastores de Cambil y Alhabar sigan llevando sus rebaños a un término sito ahora al otro lado de la línea divisoria. En otros, son las discordias civiles granadinas las que inducen a ciertos miembros de la jassa, o elite, a poner su ganado a salvo en tierra andaluza. En la primavera de 1450 el príncipe Ismail se alzó en Málaga contra el emir Muhammad el Izquierdo. Contaba con el apoyo de la población local, de los habitantes del extremo occidental del emirato y, en última instancia, del rey de Castilla. Dos notables malagueños enviaron seiscientas cabezas de ganado bovino a los términos de Olvera y Torre de Alhaquime bajo la custodia de Per Afán de Ribera, Adelantado Mayor de Andalucía. Pero, llegado el mes de julio, los susodichos abandonaron a Ismail y abrieron las puertas de la ciudad a sus enemigos, circunstancia que el Adelantado aprovecharía para quedarse con el ganado que le habían confiado. En cambio, los nueve pastores que hasta entonces habían cuidado del mismo, fueron devueltos a sus lugares de origen, Setenil y Ronda, que eran fieles a Ismail y guardaban la paz con Castilla ${ }^{17}$.También se confiaban ganados de Castilla a la protección granadina cuando aquella era presa de discordias internas. En la tregua firmada el 29 de julio de 1469 por los caudillos de la frontera oriental del emirato con el marqués de Villena, en nombre de Enrique IV, aquellos se comprometieron a no recibir los ganados y otros bienes de la gente de Lorca, o del adelantado de Murcia, rebeldes al monarca, ni a ampararles y acogerles en su territorio ${ }^{18}$.

En los fueros de la familia de Cuenca consta ya que eran los ganaderos castellanos quienes aprovechaban los pastos musulmanes. A principios del siglo XIV los vecinos de Jaén, dueños de ganado, llevaban sus rebaños a tierra de moros

15. Pero no aporta datos sobre la presencia de ganados granadinos en territorio murciano. Jiménez Alcázar 1997, p. 63. En este sentido se había manifestado ya el profesor Torres Fontes: en ocasiones se utilizaron los pastos de algunas comarcas fronterizas mediante acuerdos particulares, entre vecinos de uno y otro lado de la raya. Torres Fontes 1985, p.348.

16. Rodríguez Molina 1985, pp. 258 y 332.

17. Véase carta de Per Afán de Ribera (Los Molares, 24/julio/1450/) al concejo de Sevilla, en AMS, Actas Capitulares 1450-1452, cuad. 1450, f. 97 . Véase apéndice documental.

18. Torres Fontes 1979, p. 233. 
durante los períodos de tregua ${ }^{19}$. Un siglo más tarde ganados provenientes de la tierra de Málaga acudían a pacer en la serranía de Ronda. Lo mismo se hacía desde el otro lado de la frontera con el reino de Sevilla. Como los pastos malagueños y los de las comarcas de Gibraltar, Jerez, Alcalá de los Gazules y otros lugares de la Baja Andalucía se agostaban antes que los de los distritos más húmedos de la Serranía, ésta se configura como el centro de una trashumancia que se practicaba en sentido radial ${ }^{20}$. Algo parecido sucede con la sierra de Huéscar, en el extremo nororiental del emirato. Hasta allí se desplazaban los ganados de Baza y Guadix en busca de pastos estivales, así como los de Lorca, Murcia e incluso Orihuela. En ambos sectores de la frontera eran los pastores y vaqueros andaluces, o murcianos, quienes cruzaban la línea divisoria para apacentar sus rebaños en tierra granadina.

Los ganaderos de Lorca y Murcia pagaban derechos por herbajar en los ricos pastos de la sierra de Huéscar cada verano, que es a lo menos desde principios de mayo fasta en fin de diciembre ${ }^{21}$. El aprovechamiento de estos pastizales por el ganado lorquino está documentado de 1415 en adelante. En 1434, tras la primera conquista de Huéscar por los castellanos, los comendadores de los lugares de la Orden de Santiago quisieron aumentar las rentas percibidas del tránsito por sus encomiendas de cabezas de ganado procedentes de Lorca, Murcia y Orihuela ${ }^{22}$. Mientras Huéscar fue musulmana los ganaderos lorquinos pagaron diez reses al millar por aprovechar sus pastos ${ }^{23}$.

Los moros de la serranía de Ronda arrendaban sus pastizales a ganaderos andaluces de Zahara, Arcos, Jerez, Alcalá de los Gazules, Medina Sidonia y Gibraltar, prendiendo a aquellos que entraban en sus términos sin licencia o arrendamiento ${ }^{24}$. Además de ovinos y bóvidos, los cristianos introducían muchas piaras de cerdos en los encinares y alcornocales de Cortes, Cardela y otros términos. Los moros cobraban vacas y ovejas por las licencias y aceite cuando se trataba de cerdos. También pedían aceite cuando arrendaban pastos para bóvidos andaluces. O como pago de las multas que imponían a quienes traspasaban ilegalmente los límites con sus ganados ${ }^{25}$.

19. En 1304 Fernando IV les permite acotar sus propias dehesas pues la ruptura de hostilidades con Granada impide que su ganado herbaje en tierra de moros, "como solían acostunbrar". Rodríguez Molina 1992, p. 111.

20. Acién Almansa 1979, I, p. 114.

21. Jiménez Alcázar 1997, pp. 63-65.

22. Rodríguez Llopis 1986, pp. 230-231.

23. En 1498 los regidores de Lorca protestaron al tener que pagar 14 reses al millar en lugar de diez "como antiguamente dis que pagavan quando el dicho reino era de moros". Véase carta de los Reyes Católicos (17/septiembre/1498) sobre el particular en AGS RGS septiembre 1498, f. 52.

24. Acién Almansa 1979, III, pp. 608-610. Para Gibraltar, del mismo autor 1974-1975, pp. 245-257.

25. Los contratos eran verbales. A veces los vecinos se comprometían a proteger los hatos y los vaqueros de los moros de otras alquerías. En ocasiones también demandaban tejidos castellanos. Acién Almansa 1979, t. I, p.136, nota 284. 


\section{UNA FUENTE PARA CONOCER LA LÍNEA DIVISORIA: LOS PLEITOS SOBRE LÍMITES}

Nos hemos detenido en esta cuestión para que los lectores entiendan cómo se generó la fuente principal de información sobre la línea divisoria entre Castilla y Granada. Los concejos cristianos de la frontera interpretaron la caída del emirato granadino como un pretexto para una expansión de sus términos a la que tenían derecho por los sacrificios arrostrados anteriormente como guardianes de Andalucía y Murcia. Esta actitud, llevada a la práctica, desembocará en agrias disputas por las tierras de pasto de los vencidos. Siguiendo órdenes reales el bachiller Juan Alonso Serrano intervendrá en Ronda y su serranía a fin de que se conserven los antiguos límites entre moros y cristianos. Pero aunque lo consiga, ello no impide el desarrollo de procesos judiciales que se alargan durante años en detrimento de los mudéjares ${ }^{26}$. Gracias a este tipo de pleitos podemos saber hoy por dónde iban los límites fronterizos antes de la conquista castellana ${ }^{27}$.

Algo parecido sucede en la zona nororiental del emirato después de la toma de Baza en diciembre de 1489. A los pocos meses los mudéjares pedían a la Corona que les ayudara a conservar los antiguos mojones, porque los conçejos comarcanos les tomavan los términos que antes avían e poseyan seyendo de moros ${ }^{28}$. Particularmente enconado fue el pleito suscitado entre la localidad granadina de Castril y la villa de Cazorla, que había usurpado parte de sus términos. Pero en esta ocasión no son los mudéjares quienes reivindican la integridad de Castril, despoblada por aquel entonces, sino el secretario real Hernando de Zafra, a quien los reyes habían hecho merced del lugar ${ }^{29}$.

También hubo disputas sobre límites entre los nuevos concejos que surgen al compás de la repoblación del reino de Granada. Como la política regia fue la de mantener las lindes existentes antes de la conquista, el testimonio de los mudéjares era una vez más imprescindible. Valga como muestra el concejo de Vélez Málaga, cuyos miembros se reunían en cabildo el 20 de abril de 1493, presididos por el bachiller Juan López Navarro, corregidor de la ciudad, para saber la verdad de los términos, linderos e mojones de entre esta dicha çibdad e la çibdad de Loxa.

26. El concejo jerezano, reunido en su cabildo el 24 de mayo de 1485, dos días después de la toma de Ronda, pide a los Reyes Católicos los territorios de Cardela y Garciago invocando la sangre derramada por los suyos. López de Coca; Acién Almansa 1981, p. 329.

27. Pleitos entre Jerez y Cardela; entre Gibraltar y Casares; entre Ronda y Jerez por el lugar de Cortes; entre Casares, Gaucín y Jimena. ACM leg. 56, cuadernos 2, 27, 49 y 50.

28. Fernando e Isabel encargan (Córdoba, 2/agosto/1490) al bachiller Francisco Riquelme que atienda sus reclamaciones. García Guzmán, (1991), doc. 288, pp. 393-394. En un documento posterior leemos que los monarcas enviaron al bachiller "a pedimiento de algunos lugares de moros para que dividiese, poseyese e renovase los límites e mojones entre los tales lugares e otrosy de christianos [... J". Ibidem, doc. 318 , p. 443.

29. Por carta fechada en Écija, el 16 de febrero de 1490. García Guzmán, (1985), pp. 122-126. Añádanse los documentos publicados en García Guzmán, (1991), docs. 288 y 289; 291 y 292; 317-319 y 324. Fue el bachiller Riquelme quien devolvió a Castril sus términos "e los amojonó e dividió por do avian de yr". 
La intención era evitar debates y pleitos con esta ciudad y con la de Alhama, una vez averiguados los límites de la villa de Zalia. Incluida en la jurisdicción de Vélez Málaga, se había despoblado durante la guerra. Pese a ello, fue posible reunir a trece de sus antiguos vecinos, que vivían en diferentes alquerías del alfoz veleño. Sus testimonios tienen gran interés como se verá luego ${ }^{30}$.

De la lectura del largo pleito entre las ciudades de Vera y Lorca se deduce la existencia de una línea que separaba los territorios de ambas ciudades antes de la conquista de Granada, que se puede seguir gracias a las declaraciones de los testigos $^{31}$. La divisoria se caracterizaba por una serie de trazados rectilíneos entre los diferentes hitos o mojones, perfectamente señalizados. Había dos puntos de encuentro, siendo el primero una rábita en ruinas sita en el Cabezo de la Jara, donde confluían los límites de los términos de Lorca, Vera y Vélez Blanco. El otro era la Fuente de la Higuera, junto al antiguo camino entre Lorca y Vera. Se trataba de una gran charca dentro de una rambla a la que acudían ganados de uno y otro lado, ya que el límite pasaba por el centro de la misma. También era un lugar de encuentro para los ejeas donde se entregaban los rastros -o indicaciones de huellas- de los malhechores. Esta línea fronteriza era cruzada con frecuencia, sobre todo por los vecinos de Vera, en busca de colmenas o con ánimo de cazar. A veces se entraba en territorio del contrario con ganados en busca de pastizales. Los cruces eran sancionados con una multa o la captura de los animales y demás bienes que llevasen los contraventores ${ }^{32}$.

Los hitos o mojones podían ser accidentes naturales perfectamente reconocibles por todos. Zabratatubry, el primer mojón o límite de Zalia, que está a ojo de Archidona, según un testigo era un çerrillo que pareçe torre; o, según otro, un çerrillo que quiere pareçer torre o edefyçio. En Ayneanaga, o Fuente de Anaga, está fecho un mojón muy antiguo, de más de dos mill años, de dos pyedras fincadas una çerca de otra. Pero abundan aquí los mojones de piedras. Caso de Lindura, donde está un mojón de cantos según uno de los mudéjares declarantes; otro dice que es un mojón de pyedras ${ }^{33}$.

En la frontera rondeña, los cambios experimentados en la raya fronteriza a lo largo del siglo XV no habían logrado borrar los antiguos caminos que ahora enlazan localidades sitas a ambos lados de la divisoria. Acaso porque eran utilizados en los contactos entre las dos comunidades. Como en otros sectores de la frontera, los mojones son accidentes naturales fáciles de reconocer y, en ocasiones, alquerías abandonadas. Asensio Martín, vecino de Zahara y testigo convocado en la causa que Ronda y Jerez sostuvieron por el lugar de Cortes, declaraba el 5 de enero de 1491 que el mentado lugar ha tenido sus términos:

30. Ocho testigos vivían en Canillas de Aceituno, tres en Almayate, uno en Sedella y otro en "Almachar Alhayat". AChGr Sala 3\%/ leg. 1542/ pieza 14.

31. Expediente de límites entre Lorca y Vera. Interesa la primera parte (1511-1518): dos volúmenes que incluyen declaraciones de testigos, en su mayoría moriscos.

32. García Antón 1987, t. I, pp. 547-549. Del mismo autor 1988, pp. 377-379.

33. Supra $\mathrm{n}^{\circ} 30$. 
conosçidos e deslindados con la dicha çibdad de Xeres e con sus términos, e con los otros logares comarcanos, por los límites e mojones syguientes: dende una alquería despoblada que no sabe su nonbre, que está junto con Guadiaro, va al lomo de don Pero Ponçe e a Hos Garganta e al arroyo del Madero, e que buelve por el lomo que está baxo del lomo de la Novia, do está una penna, e de allí va al barranco de Garçiago, e de alli por la cunbre, aguas vertientes a lo de Pulgar, es término de Cortes $^{34}$.

La religión estaba presente al deslindarse los términos entre cristianos y musulmanes. Las lindes del adelantamiento de Cazorla, señorío perteneciente al arzobispado de Toledo, llegaban en su parte suroriental hasta las cercanías de la frontera con Granada, hasta el punto conocido como la enzina santa questá entre Cebas y Castril $^{35}$.En el extremo meridional de la divisoria entre el emirato nazarí y el reino de Murcia, junto al mar, había dos cabezas entrantes en él, separadas por una quebrada. Algunos testigos mencionan la existencia de un mojón en el lado granadino llamado Mahoma; en el lado murciano había otro, denominado Santiago. Ambos mojones eran derribados con frecuencia por moros y cristianos, y vueltos a levantar después ${ }^{36}$.

\section{EL TESTIMONIO DE LAS FUENTES NARRATIVAS Y LAS TREGUAS}

A la vista de lo que venimos exponiendo podría creerse que los intereses particulares de los fronterizos jugaron un papel determinante a la hora de fijar la línea divisoria. La verdad es que no estuvieron ausentes. Pero reyes y emires también estaban interesados en definir con precisión la línea fronteriza, pese a que la parca información que ofrecen las crónicas sobre este particular nos induzca a pensar lo contrario. Valga como ejemplo el relato de la "cruzada" de Martín Yáñez de Barbudo, maestre de la Orden de Alcántara, que Pero López de Ayala incluye en su crónica del rey Enrique III de Castilla. El 24 de abril de 1394 el visionario maestre llegaba a Alcalá la Real al frente de una fuerza heterogénea y con el propósito de probar en buena lid la superioridad de la fe cristiana sobre la musulmana. Alonso Fernández de Córdoba, alcaide del lugar, y su hermano Diego, Mariscal de Castilla, le recomendarán que espere la respuesta del emir a su desafío acampado a orillas del río de Azores, que es el mojon de la tierra de christianos e moros e non pasedes de ally nin entredes en la tierra de Granada ${ }^{37}$.

También son útiles los documentos que recogen las negociaciones previas a la firma de una tregua entre Castilla y Granada. Una de las cláusulas del ajuste de tregua suscrito en Madrid el 6 de octubre de 1406 menciona el acuerdo alcanzado

34. ACM. leg. 56, cuad. 27.

35. García Guzmán 1985, p.123. No se sabe si cristianos y moros compartían la creencia en la santidad del árbol.

36. García Antón 1988, p. 378.

37. López de Ayala 1992, p. 78. 
por las partes para designar unos jueces o árbitros que resuelvan tanto las querellas pendientes como las que puedan surgir más adelante. En otra leemos que el emir había ordenado hacer una torre de atalaya en el término de Bedmar, que es en tierra del maestre de Santiago, alegando que se hizo en término de Bélmez quel posee. Para resolver esta diferencia ambas partes convendrán en que se vea por los juezes que los reyers dieron para desaçer los agravios, que libren e declaren en ello lo que fallaren por derecho ${ }^{38}$. Se entiende que estos jueces deberán determinar por donde iba la línea divisoria en esa parte de la frontera. No se la menciona, pero los que oyeran hablar del asunto sabían que ahí es donde estaba el problema.

\subsection{La frontera y el derecho de fuga de los cautivos}

Al firmar una tregua ambas partes reconocían el derecho de los cautivos a escapar de sus amos. Los documentos califican este derecho de costunbre antigua, si bien el fugitivo debía devolver cualquier cosa que llevara consigo al darse por descontado que la había robado a su dueño, o a otros. Los textos de las treguas firmadas durante el siglo XIV y primera mitad del XV se muestran imprecisos respecto al punto y el momento en que el cautivo fugado ya no podía ser prendido. La mayoría señala que si el fugitivo llegare a su tierra, ni el rey de Castilla ni el emir de Granada estarán obligados a devolverlo. Si se hubiera escapado sin llevar nada consigo, deberá probarlo mediante declaraciones de testigos del logar onde saliere, los de la posada onde posare. Uno de los capítulos del ajuste de treguas acordado en octubre de 1406, dice al respecto:

Otrosi, sy fuyere cativo christiano o moro, pleyteado o non pleyteado, e llegare a su tierra, que non sean tenidos el dicho Rey de Castilla ni el dicho rey de Granada, mi señor, a lo tornar, pero que sea tornado lo que fuyere con ello de aver o de otra cosa qualquier, sy fuere fallado en su poder, e sy non fuere fallado en su poder que jure el cativo sobredicho quel non leuo ninguna cosa. E otrosi, que juren del logar onde saliere, los de la posada onde posare, quel non fuyo con ninguna cosa e sea quito el cativo sobredicho. E que sea universalmente este juiçio a los cativos de amas las partes, de los christianos e de los moros igualmente en este juiçio ${ }^{39}$.

En teoría, el cautivo recuperaba la libertad una vez que cruzara la línea divisoria. Pero, en lo que se refiere a la devolución de bienes por parte del fugitivo, se nos da a entender que éste es libre cuando llega a lugar poblado solamente. Expresado en otros términos, un cautivo huido puede ser apresado y devuelto a su dueño aunque haya cruzado la línea de separación. Habrá que esperar a la segunda mitad del Cuatrocientos, a las treguas suscritas en tiempo de Enrique IV y primeros años del reinado de Fernando e Isabel, para que la cláusula en cuestión se vuelva más precisa:

38. López de Coca Castañer 2013, p. 438.

39. Ibidem, p. 436. 
Et otrosi si algund christiano o moro cabtiuo, rescatado o por rescatar, fuyere e llegare a su tierra, siete pasadas del mojón adentro, que sea libre. E sy fuere tomado dentro en su tierra como dicho es, que la parte quel tal cativo christiano o moro bolviere, quel primer lugar do fuese llevado sea obligado a lo bolver. E si fuyere e leuare algund tesoro o otras cosas, que se buelua lo que asi leuare el tal cativo, si se fallare en su poder; e sy no se fallare en su poder, que jure el señor de la casa del primero lugar donde llegó y posó y algunos de los buenos del lugar, cada uno en su ley, antel que lo tal fuere a demanda, lo que sabe, e con esto el tal cativo sea suelto de lo que fue demandado, dándolo si lo lleuó, segund susodicho es. E que esta justicia sea igual a los cristianos e a los moros, saluo si el cabtivo christiano o moro fuere ya entregado al alhaqueque, quel tal non sea libre pues que lo ha de pagar el alhaqueque e que le sea tornado a su poder del alhaqueque demandándolo a su señor, o le sea luego fecho pagar el rescate porque se igualót ${ }^{40}$.

Así pues, en los textos tardíos el cautivo fugitivo deja de serlo en cuanto cruza la línea de demarcación. Para la mariología tampoco había duda de que la divisoria era un punto de no retorno. El cronista García de Santamaría refiere que en 1407 dos mozalbetes de Écija, Alonso García y su compañero, estaban en Antequera por rehenes de su abuelo, el primero, de un hermano el segundo. Alonso García tenía entre diez u once años, el otro, nueve. Consiguieron escapar de la ciudad y anduvieron perdidos dos noches y un día. Al amanecer del segundo día uno de los niños le propuso al otro volver a Antequera para no morirse de hambre.

E luego diz que llegó a ellos una muger fermosa e díxoles:-Andad acá, que yo vos llevaré a Teba. E fuéronse en pos della fasta Peñarrubia. E dixo el uno: -;Cata allí a Peñarrubia! E díxoles la muger:-Idos agora derechos a Teba, que no ayades miedo de cosa. E no vieron más aquella muger. E veniéronse los moços a Teba en salvo ${ }^{41}$.

La relación de este milagro, que todos atribuyeron a la Virgen del Valle, muy venerada en Écija, muestra que la sierra de Peñarrubia, sita en la comarca del Guadalteba, era uno de los hitos o mojones existentes entre la Antequera musulmana y la Teba cristiana. La simple visión de la misma era ya una garantía para cualquier fugitivo castellano ${ }^{42}$.

40. Tregua suscrita el 11 de enero de 1476, que ha sido editada en varias ocasiones. López de Coca Castañer 2005, p.345, nota 147. En la tregua de 1481 leemos: "si algun christiano o moro catibo, fuyere rescatado o por rescatar, e llegare a su tierra, del mojón dentro, siete pasados, sea libre, e si fuese tomado dentro de su tierra, como dicho es, que la parte quel tal catibo, christiano o moro, bolviere, quel lugar primero do fuere llevado, sea obligado a los bolver $\lceil. .$. ". Bonilla y Mir; Toral Peñaranda 1982, pp. 30-31.

41. García de Santamaría 1982, pp. 282-283.

42. El verbo catar equivale a ver, mirar. 


\subsection{El fisco y la línea de demarcación}

Para evitar el contrabando y asegurar el cobro de los impuestos en el comercio con el emirato de Granada, la monarquía castellana fijó puntos de control en la frontera, o puertos, donde los agentes percibían el diezmo y medio diezmo de lo morisco. Según parece la punción fiscal se ejerció a veces en ciudades y otros centros de población situados a cierta distancia de la línea divisoria. Un ejemplo: los impuestos aduaneros del sector central de la frontera, que estaban incluidos en la renta del almojarifazgo de Córdoba, se percibieron en esta ciudad hasta que en 1403 se trasladó su cobro a Alcalá la Real y Jódar, junto a la línea de demarcación. Esta tendencia se mantendrá en los años siguientes: Zahara y Antequera, conquistadas en 1407 y 1410 respectivamente, se convertirán en sendos puertos contra tierra de moros. En el obispado de Jaén, los gravámenes sobre el comercio con Granada se pagaron en la capital hasta 1438, cuando los recaudadores se trasladaron a la recién conquistada villa de Huelma ${ }^{43}$.

El número y situación de estos puertos variaba en función de las circunstancias según revelan los textos de las treguas y, sobre todo, los cuadernos de arrendamiento del diezmo y medio diezmo de lo morisco. De 1418 a 1431 estuvieron abiertos los puertos de Alcalá de los Gazules, en el obispado de Cádiz; Antequera y Zahara, en el arzobispado de Sevilla; Alcalá la Real y Lucena, en el obispado de Córdoba; Jaén, Baeza, Jódar, Quesada y Huelma, en el obispado de Jaén; Hellín, Mula y Lorca, en el obispado de Cartagena. El fisco contribuía de este modo a configurar parcialmente la línea divisoria.

\subsection{Los fieles del rastro y la delimitación territorial}

La frontera castellano-granadina distaba de ser una zona en paz durante los períodos de tregua. La naturaleza del terreno y la escasez de población favorecían a quienes querían pasar al lado contrario, sin ser descubiertos. Muchos andaluces y granadinos se ganaban la vida despojando al enemigo ancestral de todo lo que podía ser transportado: armas, ganado y personas, en el caso de éstas para pedir luego un rescate. Las incursiones de pillaje de unos, acarreaban las represalias de los otros. Siempre existió el riesgo de que las vendettas terminaran provocando un enfrentamiento general en toda la frontera. Para evitarlo, reyes y emires se preocuparon desde 1310 en designar a unos boni homines que actuaran, en sus nombres, como jueces para apaciguar los conflictos ${ }^{44}$.

La cláusula de las treguas que menciona la conveniencia de poner a estos jueces, también describe la forma en que debían actuar. Los magistrados contaban con unos rastreros, fieles del rastro, ballesteros de monte o ejeas, para seguir la pista de los delincuentes dentro del término donde habían cometido la fechoría. Pero si aquella cruzaba la linde, se la entregaban a sus homólogos del término

43. Siete años después Jaén pediría la restitución del "puerto de lo morisco".

44. Son los "jueces de las querellas" y "alcaldes entre los moros y los cristianos" en el lado castellano; en el granadino, al-qadi bayna l-muluk o "juez entre los reyes". 
vecino y, a través de la frontera, hasta reconstruir la ruta seguida por los malhechores y verificar su identidad. Si éstos no eran hallados, el juez reclamaba daños y perjuicios a los vecinos del lugar o del término en donde el rastro se perdía, según leemos en los textos de las treguas. Y si éstos probaban que el rastro no se detenía allí, quedaban obligados a que sus fieles prosiguieran la pesquisa hasta dar con el fin del rastro, o hasta que el mismo entrase en otro término.

Resulta ilustrativa la averiguación de los límites entre la taha, o distrito, de Zalia y las ciudades de Loja, Alhama y villa de Archidona promovida por el corregidor de Vélez Málaga en abril de $1493^{45}$.Los testigos declarantes habían sido en su mayoría fieles del rastro. Uno de ellos recuerda que un cristiano mató a un moro en el campo de Zafarraya hacia 1480, le persiguieron y entregaron el rastro a los de Loxa en Guaidai Guaxilei, e que después de entregado el dicho rastro que los de Loxa fueron tras él e lo tomaron e tornaron ¡... J. Otro testigo declara que acompañó una vez al alcaide de Zalia hasta el mojón de Guaidai Guexiley, donde el alcaide se detuvo porque hera término de la dicha çibdad de Loxa, y le dijo que allí se entregaban los rastros la dicha Çalia e la dicha Loxa. En el caso de Archidona, los rastros se entregaban en el mojón conocido como Zabratatubry ${ }^{46}$.

La viabilidad de este sistema para controlar la violencia fronteriza fue mayor de lo que comúnmente se ha venido aceptando ${ }^{47}$. Aquí nos interesa subrayar que la labor de estos rastreros pone de manifiesto la existencia de unos límites territoriales conocidos por todos: ya sea la línea divisoria o las lindes de los diferentes términos y jurisdicciones existentes a uno y otro lado de aquella. Llama la atención, en este sentido, ver cómo los salteadores evitaban unos términos al cruzar la frontera y seguían otros, con objeto de que pagasen justos por pecadores en el caso de que hubiera represalias. En una carta enviada por el hachib "Monfarrax" al concejo de Alcalá la Real el 19 de diciembre de 1461, el alto dignatario granadino reprocha a los munícipes que permitan a algunos de sus vecinos ayudar a los de Jaén, los cuales vyenen por vuestros términos salvos e seguros, e allegan fasta los mojones de tierra de moros, e facen su cabalgada en tierra de moros $\{. . . J$. No ocurre igual del lado granadino, cuyos almogávares van desde Íllora, Moclín y Colomera a la sierra de Jaén, "e non entran en término de Alcalá un palmo". Y añade que podrían, si quisieran, prohibir a los de Jaén que entrasen en tierra de moros por su término:

Que bien pueden los de Jahen entrar a tierra de Granada o de Guadix, o a Basta, o a donde quisieren, e non por vuestro término. Que el almogávar non quiere salvo su entrada sea seguro, que la salida non avra miedo; pues que non fue sentido a la entrada ${ }^{48}$.

45. Supra, $\mathrm{n}^{\mathrm{0}} 29$.

46. O Cartatatubry según otro testigo.

47. López de Coca Castañer 2010, pp. 273-301.

48. Supra, pp. 185-186. 


\section{6. ¿Hubo UnA TIERRA DE NADIE?}

El profesor Torres Fontes, máximo conocedor de la frontera del reino de Murcia con Granada, calificaba la línea divisoria y los territorios adyacentes de verdadera tierra de nadie ${ }^{49}$. Aunque su origen es, probablemente, más antiguo, esta locución se ajustaba a la realidad de la guerra de trincheras en el norte de Francia y Flandes durante la Primera Guerra Mundial. Desde entonces se ha venido usando para designar el territorio no ocupado entre dos frentes enemigos o, mejor, el territorio sin dueño. Pero no era éste el caso de la frontera granadina según se ha podido comprobar. La supuesta tierra de nadie, si bien estaba desprovista de explotaciones agrarias y población permanente, se veía muy concurrida en tiempo de tregua por cazadores, leñadores, carboneros y ganaderos. Véase el testimonio indirecto que ofrece Fernán Pérez del Pulgar en su carta a Pedro Navarro (El Salar, 6/abril/1509) recomendándole que aproveche la experiencia de los veteranos de la guerra de Granada en la próxima campaña en África del Norte. Le aconseja que se sirva, entre otros, de atalayas, o escuchas, capaces de diferenciar las polvaredas generadas por hombres, a pie y a caballo, de los simples torbellinos o el polvo levantado por el ganado. Que puedan, asimismo, distinguir durante el día entre el humo de los carboneros y la ahumada, o señal de alarma; y que no confundan la almenara-versión nocturna de la ahumada- con la candela de los ganaderos ${ }^{50}$.

Pero hubo excepciones. El uso y costumbre de la frontera permitían que un gobernante pudiera asolar un lugar a él perteneciente en circunstancias concretas. Don Juan Manuel (1282-1348) recomienda al príncipe que las fortalezas que no pueda defender o, las derribe, o las dexe de tal manera quel non pueda dellas venir danno ${ }^{51}$. En algunos textos de treguas se dice, además, que las fortalezas derrocadas no podían reconstruirse en tiempo de paz. En el tratado suscrito por Fernando IV con el emir Nasr en 1310, éste acepta entregar al castellano algunos castillos fronteros. En contrapartida, su adversario promete no impedirle que construya en su tierra o derribe en sus lugares lo que quisiere saluo en estos lugares que nos auedes a entregar, et los castiellos derribados que se non labren ${ }^{52}$.

Ahora bien, si la parte granadina consideraba que un lugar yermo no tenía dueño la castellana sostenía, por el contrario, que bastaba con tomar posesión del mismo para considerarlo como propio, según se aprecia en lo ocurrido con la fortaleza de Priego. Abandonada por los musulmanes en septiembre de 1407, después de la toma de Zahara por los cristianos, éstos se limitaron a tomar posesión de la misma. Al cabo de un año vuelven para ocuparla y los moros se lo impiden por la fuerza pese a la tregua en vigor. El emir Yusuf III responderá al emisario del rey de Castilla, Gutierre Díaz, que su señor no había poblado Priego, e quedó por yermo. E siendo yermo, no estava por él ni por los moros. Tras la firma de las treguas ha

49. Torres Fontes 1985, p. 347.

50. Carriazo y Arroquia 1946, p. 123.

51. Blecua (ed.) 1982, t. I, p. 334.

52. Giménez Soler 1908, p. 168. La cursiva es mía. 
querido ocuparlo sin razón ni derecho. De ahí que sus súbditos pudieran hacer lo que fizieron en no dexar poblar la tierra que no quedó por suya ni por mía ${ }^{53}$.

A estas alturas los granadinos estaban más que al tanto de la mentalidad castellana. La costumbre de tomar posesión de un lugar o un territorio, difiriendo su ocupación efectiva para un futuro más o menos mediato, era muy antigua. Alfonso VI de Castilla invade el reino abbadí de Sevilla en 1082 y, al llegar a la playa de Tarifa, entra en el mar a caballo y toma posesión del último confín de España en una ceremonia de gran valor simbólico. En 1126 será Alfonso I de Aragón quien, al llegar a la playa de Vélez Málaga, suba a una barca y coma luego un pez recién capturado. Ibn Sairafi escribe, extrañado: ¿Era éste un voto que habia formulado y cumplía ahora, o bien lo hacía sólo para que se hablara luego de él?. Lo ignoro ${ }^{54}$. En esta ocasión el monarca aragonés, aparte de tomar posesión de los confines de España comía sus frutos antes de emprender la retirada.

\section{CONCLUSIONES}

Hubo una franja fronteriza cuyas dimensiones variaban según la perspectiva de quien la contemplase. Cuatro o cinco leguas en el caso de los almogávares, doce si se trataba de agentes del fisco real que perseguían a los descaminados, o diez leguas de anchura cuando se contaba el número de cabezas de ganado que pacían cerca de la divisoria con Granada, para impedir que la cruzaran subrepticiamente.

En cambio, está por demostrar que hubiera una banda neutral entre los límites de las tierras de cristianos y los mojones de las tierras musulmanas y que andaluces y granadinos compartieran su explotación pecuaria. Tampoco hay pruebas de que se diera una trashumancia de doble sentido. Contrasta la relativa abundancia de datos sobre ganaderos y pastores, andaluces y murcianos, que arrendaban el uso de los pastizales sitos en territorio nazarí, con la práctica ausencia de noticias sobre los rebaños y hatos de granadinos que pasaran a pacer al otro lado de la línea de demarcación.

Las disputas por el aprovechamiento de estos pastos tras la desaparición del emirato nazarí son una fuente inestimable para conocer la línea divisoria. Hasta el punto de que ha sido posible reconstruirla con detalle en alguno de sus tramos. El conocimiento de por dónde iba la línea de separación interesaba a las poblaciones comarcanas y a los gobernantes pues había que dilucidar a partir de dónde un fugitivo cristiano o musulmán podía considerarse libre, así como delimitar el

53. Gutierre Díaz replica en los siguientes términos: "Señor, no es razon lo que dezides, ca este lugar e otro qualquier que los moros dexaren en guerra yermos $\lceil\ldots$. e los christianos entrasen en ellos, luego serian suyos. E así, como este lugar de Priego fuese del Rey nuestro señor, que lo ganó el Infante, luego tomó la posesión dél e quedó por suyo, así como quedaron los otros lugares $[\ldots \mid$ E estando en si suyo se fizo la tregua; e razon fiso en lo poblar [.. \". Una exposición más detallada de los hechos en García de Santamaría 1982, pp. 157-158, 188-189 y 252-254.

54. En su Kitab al-anwan al-jalida (historia almorávide hoy perdida) según la versión de Ibn al-Jatib. Dozy 1881, t. I, pp. 359-360. 
ámbito de actuación de los jueces de las querellas. Sin olvidar, además, el traslado a las cercanías de la raya de algunos de los puertos donde se gravaba fiscalmente el comercio con Granada; una prueba, quizá, de que la Hacienda Real de Castilla también estuvo interesada en configurar la línea divisoria.

Ninguna de las características de la frontera castellano-granadina se ajusta al concepto de tierra de nadie, si exceptuamos la costumbre de considerar las fortalezas derribadas o abandonadas como lugares yermos y, por tanto, carentes de dueño. Pero, como se ha visto, castellanos y granadinos tenían puntos de vista diferentes sobre el particular.

\section{APÉNDICE DOCUMENTAL}

1450, julio, 24. Los Molares

El adelantado Per Afán de Ribera se niega a devolver el ganado perteneciente a un notable malagueño porque se ha pasado a los enemigos del emir Ismael, vasallo del rey de Castilla

AMS Actas Capitulares 1450-1452, cuad. 1450, f. 97

"Honrados alcalldes mayores e alguasyl mayor, veynte e quatro cavalleros, jurados, ofiçiales omes buenos de la muy noble e muy leal çibdad de Sevilla, señores parientes e amigos. Una letra vuestra en viernes veynte e quatro días de jullio que mi primo Pero Fernandes Melgarejo me troxo e oy la creençia que de vuestra parte me dixo, el qual ha andado algunos días en mi busca, por quanto yo partí de la villa de Osuna con entençion de llegar a la mi villa de la Torre de Alhaquin, sobre algunas cosas cunplideras a serviçio del rey nuestro señor. El qual como sopo de mi partida se bolvió del camino çerca de la dicha de Osuna.E todo ello entendido, desis señores que los moros han enbiado a requerir que fasta seysçientas cabeças de ganado vacuno e nueve moros que por mi fueron traídas de su tierra las fuesen tornadas, de no, que la pas se quebrantaría e que quanto daño desto viene a la tierra a mí será bien conoçido; e que me plega de lo mandar bolver porque vos paresçe que tienen alguna razón de se quexar.

Es verdad señores parientes, como es a todos notorio el rey nuestro señor me encargó e mandó que yo tomase cargo de los fechos del rey don Ysmael, su vasallo, e aquellos favoresçiese. En ayuda del qual ha dos meses que por serviçio del rey nuestro señor, a mi sueldo e propias espensas, yo he andado fasta que él fue en poder de sus enemigos, donde todo el daño que yo pudiera faser a sus contrarios lo pusiera en obra, según que el rey nuestro señor me era mandado. E como estas vacas fuesen de Reduan de las Fijas e de otro su conpañero, los quales durante que siguieron el serviçio del dicho rey don Ysmael las troxieron en el término de Olvera e de mi tierra de la Torre de Alhaquin, por mí fueron bien guardadas, que daño alguno non reçibieron. Mas después que yo sope que estos prinçipalmente fueron los que dieron la entrada a sus enemigos en la çibdad, yo ove rasonable cabsa de les faser todo el mal e daño que pudiera como a sus contrarios e deservidores, e mandé tomar las dichas vacas en el término de la dicha mi villa de la Torre. E puesto que, señores parientes, yo non sea obligado a dar cuenta de cosa desto salvo al rey nuestro señor, por cuio mandado yo he fecho todo lo susodicho, acatando el grande amor e naturalesa que en esa muy noble çibdad yo he e el acatamiento en que la yo tengo, seré contento de vos mostrar cada que vos plasera como de su voluntad e mandamiento lo yo avía fecho. 
Quanto a la guarda de la pas que desides es puesta, a esto señores parientes, yo no sé quien la puso ni por tenía abtoridad ni mandamiento fue asegurado ni conmigo tal cosa se consultó ni me fue fecho saber cómo de rason deviera sy por vos, señores, o por otros en la tierra se fisiera, pues que en la frontera tanta parte como él que más tenía e el dicho señor rey sienpre en éste e en todos los otros fechos le plugo e ha plasido conmigo los mandar comunicar como en qualquiera de los grandes de su reyno, e non me pareçía syn rrasón pues es çierto que su señoría así lo ha fecho e fase, que sy vosotros alguna pas teníades asentada o queryades asentar lo consultaredes conmigo, pues della o de la guerra tanta parte me cabía. E yo, señores, fasta agora, ninguna pas e seguro no he tenido con los del reyno de Granada salvo con Ronda e Setenil, ni para faser la dicha tregua ni pas he avido mandamiento del rey nuestro señor ni de otro que su poder tenga. Por tanto, yo no era obligado de guardar otra ninguna salvo aquella que yo tengo puesta, la qual fasta agora tengo bien guardada, e por la toma de las dichas vacas yo no la quebranté pues eran de aquellos a quien yo non tenía asegurado ni tenía mandamiento del rey nuestro señor para les guardar pas; e los moros que eran de Ronda e Setenil, luego los mandé bolver. E çerca desto, señores, no se qué otra cosa vos escribo syno que vos pido de graçia e merçed que creedes al dicho mi primo. Mantenga vos Dios.

De Los Molares, XXIIII de julio. El adelantado".

\section{BiBLIOGRAFÍA CITADA}

Acién Almansa, Manuel (1974-1975), "Dos textos mudéjares de la serranía de Ronda", Cuadernos de Estudios Medievales, II-III, pp. 245-257.

Acién Almansa, Manuel (1979), Ronda y su serranía en tiempo de los Reyes Católicos, Málaga, 3 vols.

Argente del Castillo Ocaña, Carmen (1988), "Los aprovechamientos pastoriles en la frontera granadina". Actas del V Coloquio Internacional de Historia Medieval de Andalucía, Córdoba, pp. 271-280.

Blecua, José M. (ed.) (1982), Don Juan Manuel. Obras Completas, Madrid, 2 vols.

Bonilla y Mir, José Antonio; Toral Peñaranda, Enrique (1982), El tratado de paz de 1481 entre Castilla y Granada, Jaén.

Carmona Ruiz, María Antonia (2009), "Los aprovechamientos pastoriles en la frontera entre los reinos de Sevilla y Granada, siglos XIII al XV", En la España medieval, 32, pp. 249-272.

Carriazo y Arroquia, Juan de Mata (1946), "Cartas de la frontera de Granada", $\mathrm{Al}$ Andalus XI, pp. 29-84.

Dozy, René (1881), Recherches sur l'histoire et la litterature de l'Espagne au Moyen Âge, Leiden, 2 vols.

Escavias, Pedro de (1940), Hechos del condestable Don Miguel Lucas de Iranzo (Crónica del siglo XV), Ed. Juan de M. Carriazo, Madrid.

García Antón, José Antonio (1987), "Cautiverios, canjes y rescates en la frontera entre Lorca y Vera en los últimos tiempos nazaríes", Homenaje al profesor Juan Torres Fontes, Murcia, pp. 547-559. 
García Antón, José Antonio (1988), "Relaciones fronterizas entre los reinos de Murcia y Granada en los finales del siglo XV. Aspectos militares", Actas del V Coloquio Internacional de Historia Medieval de Andalucía, Córdoba, pp. 377-384.

García Guzmán, María del Mar (1985), El Adelantamiento de Cazorla en la Baja Edad Media. Un señorío eclesiástico en la frontera castellana, Cádiz.

García Guzmán, Ma del Mar(1991), Colección diplomática del Adelantamiento de Cazorla (1231-1495), Cádiz.

García de Santamaría, Alvar (1982), Crónica de Juan II, Ed. Juan de M. Carriazo, Madrid.

Gautier-Dalche, Jean (1959),'Islam et Chretienté en Espagne du XIIè siécle. Contribution à l'étude de la notion de frontière", Hesperis 4, pp. 183-217.

Giménez Soler, Andrés (1908), La Corona de Aragón y Granada. Historia de las relaciones entre ambos reinos, Barcelona.

Jiménez Alcázar, Juan Francisco (1997), Un concejo de Castilla en la frontera de Granada: Lorca (1460-1521), Granada.

Lafuente Alcántara, Miguel (1992), Historia de Granada, t. III (ed. y estudio preliminar Pedro Gan Jiménez), Granada (reproducción facsímil de edición de Granada, 1843).

López de Ayala, Pedro (1992), Coronica de Enrique III, ed. C.L.Wilkins y H.M. Wilkins, Madison.

López de Coca Castañer, José Enrique; Acién Almansa, Manuel (1981), "Los mudéjares del obispado de Málaga (1485-1501)", I Simposio Internacional de Mudejarismo, Madrid-Teruel, pp. 367-407.

López de Coca Castañer, José Enrique (2005), "El reino de Granada: ¿un vasallo musulmán?”, IX Congreso de Estudios Medievales, León, pp. 313-346.

López de Coca Castañer, José Enrique (2009), "La frontera de Granada (s. XIII$\mathrm{XV}$ ): el comercio con los infieles", XI Congreso de Estudios Medievales, León, pp. 369-392.

López de Coca Castañer, José Enrique (2010), "Los jueces de las querellas”, Edad Media. Revista de Historia 11, pp. 173-201.

López de Coca Castañer, José Enrique (2013), "Un ajuste de treguas entre Castilla y Granada (1406)", Mutge, Josefina; Salicru, Roser; Vera, Carles (eds.), La Corona Catalanoaragonesa, l'Islam i el Mon Mediterrani: Estudis d'Història Medieval en Homenatge a la Doctora Maria Teresa Ferrer i Mallol, Barcelona, pp. 427-438.

Pérez Boyero, Enrique (1997), Moriscos y cristianos en los señoríos del Reino de Granada (1490-1568), Granada.

Rodríguez Llopis, Miguel (1986), Señoríos y feudalismo en el reino de Murcia, Murcia.

Rodríguez Molina, José (ed.) (1985), Colección diplomática del Archivo Histórico Provincial de Jaén. Siglos XIV y XV, Jaén.

Rodríguez Molina, José (1987), "Banda territorial común entre Granada y Jaén", José Enrique López de Coca Castañer (ed.), Estudios sobre Málaga y el reino de Granada en el V Centenario de la Conquista, Málaga, pp. 113-130. 
Rodríguez Molina, José (1992), "Relaciones pacíficas en la frontera con los reinos de Córdoba y Jaén", Revista del Centro de Estudios Históricos de Granada y su Reino 6, pp. 81-128.

Rodríguez Molina, José (1997), "Relaciones pacíficas en la frontera con el reino de Granada", Actas del Congreso "La frontera oriental nazarí como sujeto histórico (s. XIII-XVI)”, Almería, pp. 253-288.

Rodríguez-Picavea Matilla, Enrique (2001), "La ganadería en la economía de frontera. Una aproximación al caso de la meseta meridional castellana en los siglos XI-XIV”, Identidad y representación de la frontera en la España medieval (siglos XI-XIV)", Madrid, pp. 181-204.

Rojas Gabriel, Manuel (1995), La frontera entre los reinos de Sevilla y Granada en el siglo XV (1390-1481), Cádiz.

Seco de Lucena Paredes, Luis (1958), "El juez de la frontera y los fieles del rastro", Miscelánea de Estudios Árabes y Hebraicos, VII-1, pp. 137-140.

Suárez Fernández, Luis (1982), Historia del reinado de Juan I de Castilla, Madrid, 2 vols.

Torres Fontes, Juan (1985), "El adalid en la frontera de Granada", Anuario de Estudios Medievales 15, pp. 345-366.

Torres Fontes, Juan (1979), "Las treguas con Granada de 1469 y 1472”, Cuadernos de Estudios Medievales, IV-V, pp. 211-236. 